\title{
Comparative Study between Airway Pressure Release Ventilation and Synchronized Intermittent Mandatory Ventilation in Treatment of Acute Respiratory Distress Syndrome
}

\author{
Abo Bakr Helal El-Asmar, Taha Abd Elhamid Awad, Ahmed Attia El-Didamony \\ Department of Chest Diseases, Faculty of Medicine, Al-Azhar University, Cairo, Egypt \\ Corresponding author: Ahmed Attia El-Didamony, email: dr_a.attia@yahoo.com
}

\begin{abstract}
Background: Various animal and human studies have demonstrated that airway pressure release ventilation (APRV) may have advantages over conventional ventilation in the management of acute respiratory distress syndrome (ARDS); however, it is still not used consistently because of the few studies in this regard.

Aim of the work: The aim of this work is to compare outcomes of APRV in patients with ARDS with synchronized intermittent mandatory ventilation (SIMV) where positive end expiratory pressure (PEEP) is used.

Patients and methods: the study included (50) patients with ARDS, they were randomly divided into two groups, group (A) patients were given APRV pattern, and group (B) patients were given (SIMV+PEEP). Data were obtained before and throughout the period of mechanical ventilation and up to 60 days. Changes in arterial blood gases, hemodynamics and LIS and outcome measures were compared in both groups.

Results: demographic and baseline clinical data were similar in both groups with no differences. Follow up data showed that APRV was associated with better oxygenation, less ICU length of stay, more ICU-free days, less ventilation days, more ventilator free days and more sedation free days in comparison to SIMV+PEEP ( $>0.05$ ). However, there were no significant differences between groups regarding mortality, length of hospital stay and rates of tracheostomy and successful extubation $(\mathrm{p}<0.05)$. Conclusion: In comparison to SIMV+PEEP, APRV can significantly improve oxygenation, decrease need for sedatives, increase free ventilation days and shorten duration of ICU stay; however, APRV has no advantage over SIMV+PEEP regarding mortality.
\end{abstract}

Key words: Acute respiratory distress syndrome, Airway pressure release ventilation, mechanical ventilation.

\section{INTRODUCTION}

Acute respiratory distress syndrome (ARDS) is the most severe form of acute lung injury (ALI) which still has high rates of morbidity and mortality. Mechanical ventilation stills the backbone of patient management (1). One of the newly developed and successfully used strategies in patients with ARDS is lung protective strategies (LPS). However, use of low tidal volumes during LPS may be associated with atelectasis due to decreased alveolar inflation ${ }^{(2)}$.

Airway pressure release ventilation (APRV) is one of newly introduced modes in ARDS management. It is a pressure controlled mode that uses two levels of pressures with inverted ratio ventilation. Release of airway pressure during APRV simulates expiration while elevated baseline pressure improves oxygenation. One of the advantages of this mode is that it allows spontaneous breathing ${ }^{(3)}$. In clinical practice, APRV has shown to be safe and comfortable for ARDS patients as it can decrease the risk of ventilator-induced lung injury, does not adversely affect hemodynamics and because of spontaneous breathing it can reduce patient-ventilator asynchrony (4)

\section{PATIENTS AND METHODS \\ Study design}

This study was carried out on fifty (50) patients diagnosed as having ARDS according to Berlin definition, were mechanically ventilated in the
Respiratory I.C.Us at Al-Azhar University Hospitals (Al-Hussein and Bab Elshareya). This study was conducted over thirty months-period, from October 2016 to April 2019. The exclusion criteria of the study were as follows: age of $<18$ years or $>60$ years, presence of significant chronic pulmonary disorder (chronic obstructive pulmonary disease, idiopathic pulmonary fibrosis, suppurative lung disease or diffuse alveolar hemorrhage) or presence of cardiac disorder (rheumatic or ischemic heart disease).

The study was approved by the local Ethics Committee and informed written consent from the patients was obtained before enrollment in the study.

\section{Methods}

All patients underwent the followings:

1- Full clinical history taking

2- Complete clinical examination, including both local and general examinations.

3- Determination of associated significant comorbidities.

4- Routine laboratory testing with certain emphasis on (complete blood picture, liver function test, serum creatinine, serum sugar, ESR and arterial blood gases serial analysis).

5- Chest x-ray. 
6- Determination of body mass index (BMI), (APACHE) III score and lung injury score (LIS).

7- ECG and echocardiography to exclude left sided heart failure.

8- Patients were divided randomly into 2 groups:

Group A (25 patients): managed by airway pressure release ventilation mode.

Group B (25 patients): managed by using synchronized intermittent mandatory ventilation mode and positive end expiratory pressure. (SIMV+PEEP), low tidal volume ventilation.

9- Follow up ABG, LIS and hemodynamics after 24 hours of ventilation.

12- Determination of clinical outcomes as length of ICU stay, ICU-free days, total ventilator days, ventilator-free days, free sedatives days, 28 and 60 days mortality, rate of successful extubation, tracheostomy rate and need for intercostal tube insertion for barotrauma.

\section{Statistical analysis}

Data were analyzed using the Statistical Package for the Social Sciences (SPSS); version 17.0. For descriptive statistics: the mean $\pm \mathrm{SD}$ was used for quantitative variables while the number and percentage were used for qualitative variables. Qualitative variables were compared by Fischer's exact test (FET), and quantitative variables were compared by independent samples t-test. The statistical methods were verified, assuming a significant level of $\mathrm{p}<0.05$ and a highly significant level of $\mathrm{p}<0.001$.

\section{RESULTS}

Statistically, there were no significant differences between groups regarding age, gender, BMI and associated co-morbidities (Table 1).

Table (1): Comparison of demographic variables, BMI and associated Co-morbidities in studied groups.

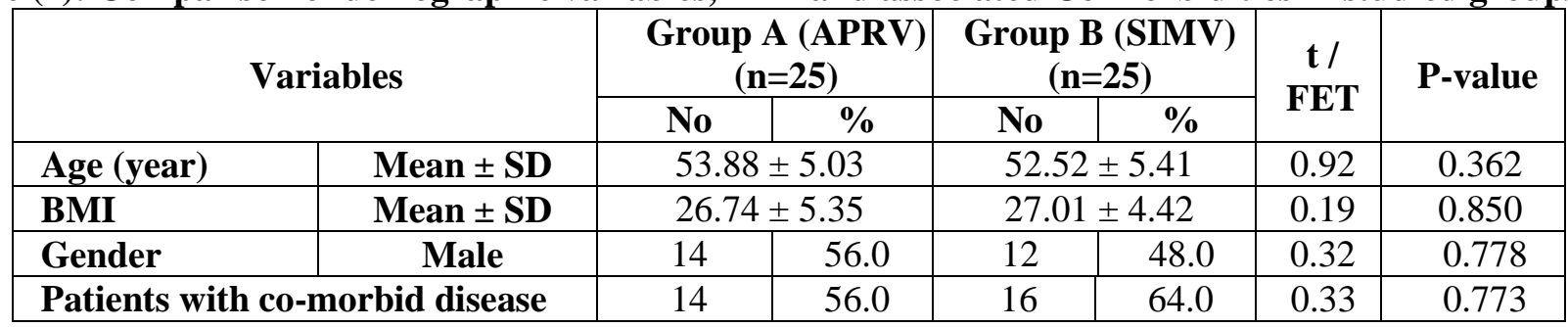

No significant differences were present between groups regarding baseline heart rate, respiratory rate, mean arterial blood pressure and central venous pressure. Also, baseline lung injury score (LIS) and the APACHE III score were similar in both groups without significant differences (Table 2).

Table (2): Comparison of baseline clinical characteristics, Lung injury score and APACHE III score.

\begin{tabular}{|l|c|c|c|c|}
\hline \multirow{2}{*}{ Variables } & $\begin{array}{c}\text { Group A (APRV) } \\
(\mathbf{n = 2 5})\end{array}$ & $\begin{array}{c}\text { Group B (SIMV) } \\
(\mathbf{n = 2 5})\end{array}$ & \multirow{2}{*}{ t } & \multirow{2}{*}{ P-value } \\
\cline { 2 - 3 } & Mean \pm SD & Mean \pm SD & & \\
\hline HR (beat/min) & $116.20 \pm 7.84$ & $119.12 \pm 6.75$ & 1.41 & 0.164 \\
\hline RR (cycle/min) & $41.44 \pm 7.47$ & $39.76 \pm 6.91$ & 0.83 & 0.413 \\
\hline MAP (mmHg) & $78.49 \pm 21.62$ & $80.04 \pm 20.91$ & 0.26 & 0.798 \\
\hline CVP (mmHg) & $8.06 \pm 4.03$ & $7.32 \pm 3.53$ & 0.69 & 0.493 \\
\hline Lung injury score & $2.76 \pm 0.84$ & $2.85 \pm 0.70$ & 0.44 & 0.663 \\
\hline APACHE-III score & $88.08 \pm 13.25$ & $91.08 \pm 12.56$ & 0.82 & 0.415 \\
\hline
\end{tabular}

Follow up 24 hours after ventilation revealed improvement of these clinical variables (heart rate, respiratory rate, mean arterial blood pressure) with non-significant differences between groups; however, LIS was significantly improved with APRV in group A (Table 3).

Table (3): Comparison of clinical characteristics and Lung injury score 24 hours after ventilation.

\begin{tabular}{|l|c|c|c|c|}
\hline \multirow{2}{*}{ Variables } & $\begin{array}{c}\text { Group A (APRV) } \\
(\mathbf{n = 2 5})\end{array}$ & $\begin{array}{c}\text { Group B (SIMV) } \\
(\mathbf{n = 2 5})\end{array}$ & \multirow{2}{*}{ t } & \multirow{2}{*}{ P-value } \\
\cline { 2 - 3 } & Mean \pm SD & Mean \pm SD & & \\
\hline HR (beat/min) & $106.68 \pm 9.42$ & $109.80 \pm 7.09$ & 1.32 & 0.192 \\
\hline RR (cycle/min) & $34.08 \pm 3.78$ & $35.20 \pm 4.07$ & 1.01 & 0.319 \\
\hline MAP (mmHg) & $81.49 \pm 18.80$ & $82.30 \pm 18.44$ & 0.15 & 0.879 \\
\hline Lung injury score & $2.22 \pm 1.03$ & $2.78 \pm 0.84$ & 2.09 & $0.042 *$ \\
\hline
\end{tabular}

*: Significant. 
Baseline arterial blood gas measurements $\mathrm{pH}, \mathrm{PaO}_{2} \mathrm{PaCO}_{2}$ and $\mathrm{PaO}_{2} / \mathrm{FIO}_{2}$ in group A (APRV) were similar to those in group B (SIMV+PEEP) with no significant differences (Table 4). After 24 hours of ventilation, $\mathrm{pH}$ and $\mathrm{PaCO}_{2}$ were similar in both groups without significant differences. However, $\mathrm{PaO}_{2} / \mathrm{FIO}_{2}$ ratio was significantly improved in APRV managed patients (Table 5).

Table (4): Comparison of baseline gasometric variables in studied groups.

\begin{tabular}{|l|c|c|c|c|}
\hline \multirow{2}{*}{ Variables } & $\begin{array}{c}\text { Group A (APRV) } \\
(\mathbf{n = 2 5})\end{array}$ & $\begin{array}{c}\text { Group B (SIMV) } \\
(\mathbf{n = 2 5})\end{array}$ & \multirow{2}{*}{ FET } & \multirow{2}{*}{ P-value } \\
\cline { 2 - 4 } & Mean \pm SD & Mean \pm SD & & \\
\hline $\mathbf{p H}$ & $7.40 \pm 0.07$ & $7.39 \pm 0.06$ & 0.24 & 0.812 \\
\hline $\mathbf{P a O}_{2}\left(\mathbf{m m H g}_{2}\right)$ & $44.08 \pm 4.12$ & $45.00 \pm 3.75$ & 0.83 & 0.413 \\
\hline $\mathbf{P a C O}_{2}\left(\mathbf{m m H g}_{2}\right)$ & $29.80 \pm 6.10$ & $31.84 \pm 5.41$ & 0.1 .25 & 0.217 \\
\hline $\mathbf{P a O}_{2} / \mathbf{F I O}_{2}$ & $129.44 \pm 48.62$ & $136.88 \pm 51.65$ & 0.52 & 0.602 \\
\hline $\mathbf{P a O}_{2} / \mathbf{F I O}_{2}<\mathbf{1 5 0} \mathbf{n}(\%)$ & $16(64.0)$ & $15(60.0)$ & 0.09 & 1.000 \\
\hline
\end{tabular}

Table (5): Comparison of gasometric variables 24 hours after ventilation in studied groups.

\begin{tabular}{|l|c|c|c|c|}
\hline \multirow{2}{*}{ Variables } & Group A (APRV) $(\mathbf{n = 2 5})$ & Group B (SIMV) $(\mathbf{n = 2 5})$ & \multirow{2}{*}{ t } & \multirow{2}{*}{ P-value } \\
\cline { 2 - 3 } & Mean \pm SD & Mean \pm SD & 0.76 & 0.449 \\
\hline pH & $7.41 \pm 0.04$ & $7.40 \pm 0.05$ & 1.16 & 0.253 \\
\hline PCO $_{2}(\mathbf{m m H g})$ & $30.08 \pm 6.28$ & $32.08 \pm 5.93$ & 4.57 & $<0.001 *$ \\
\hline PO $_{2} /$ FIO $_{2}$ & $214.88 \pm 47.03$ & $150.52 \pm 52.40$ & \\
\hline
\end{tabular}

*: Significant.

Regarding outcomes, there was no significant difference between groups in hospital length of stay. Application of APRV in group (A) was significantly associated with a less ICU length of stay (days), more ICU-free days, less total ventilator days and more ventilator free days at day 28 in comparison to SIMV+PEEP with (B) group. There was a significant increase in number of sedation free days with APRV in (A) group (Table 6).

Table (6): Comparison of outcome characteristics in studied groups.

\begin{tabular}{|l|c|c|c|c|}
\hline \multirow{2}{*}{\multicolumn{1}{|c}{ Variables }} & $\begin{array}{c}\text { Group A (APRV) } \\
(\mathbf{n = 2 5})\end{array}$ & $\begin{array}{c}\text { Group B (SIMV) } \\
(\mathbf{n = 2 5})\end{array}$ & \multirow{2}{*}{ t } & \multirow{2}{*}{ P-value } \\
\cline { 2 - 3 } & Mean \pm SD & Mean \pm SD & & \\
\hline Hospital length of stay (days) & $20.16 \pm 7.05$ & $20.00 \pm 6.23$ & 0.09 & 0.933 \\
\hline ICU length of stay (days) & $14.04 \pm 6.00$ & $17.44 \pm 5.55$ & 2.08 & $0.043 *$ \\
\hline ICU-free days & $5.96 \pm 4.61$ & $2.56 \pm 2.62$ & 3.21 & $0.002 *$ \\
\hline Total ventilator days & $11.84 \pm 5.04$ & $15.52 \pm 5.72$ & 2.42 & $0.022^{*}$ \\
\hline Ventilator-free days & $8.28 \pm 5.36$ & $4.44 \pm 4.18$ & 2.82 & $0.007 *$ \\
\hline Free sedatives days & $17.56 \pm 6.80$ & $13.64 \pm 5.75$ & 2.20 & $0.033^{*}$ \\
\hline
\end{tabular}

*: Significant.

No significant differences were identified between groups regarding rate of successful extubation, rate of tracheostomy or incidence of pneumothorax (Table 7).

Table (7): Comparison of successful extubation, tracheostomy rate and incidence of pneumothorax in studied groups.

\begin{tabular}{|c|c|c|c|c|c|c|c|}
\hline \multirow{2}{*}{\multicolumn{2}{|c|}{ Variable }} & \multicolumn{2}{|c|}{$\begin{array}{c}\text { Group A (APRV) } \\
(\mathbf{n}=\mathbf{2 5})\end{array}$} & \multicolumn{2}{|c|}{$\begin{array}{c}\text { Group B (SIMV) } \\
(\mathbf{n}=25)\end{array}$} & \multirow[t]{2}{*}{ FET } & \multirow[t]{2}{*}{ P-value } \\
\hline & & No & $\%$ & No & $\%$ & & \\
\hline \multirow{2}{*}{$\begin{array}{l}\text { Successful } \\
\text { extubation }\end{array}$} & Yes & 14 & 56.0 & 12 & 48.0 & \multirow{2}{*}{0.32} & \multirow{2}{*}{0.778} \\
\hline & No & 11 & 44.0 & 13 & 52.0 & & \\
\hline \multirow{2}{*}{ Tracheostomy } & Yes & 4 & 16.0 & 7 & 28.0 & \multirow{2}{*}{1.05} & \multirow{2}{*}{0.496} \\
\hline & No & 21 & 84.0 & 18 & 72.0 & & \\
\hline \multirow{2}{*}{ Pneumothorax } & Yes & 1 & 4.0 & 2 & 8.0 & \multirow{2}{*}{0.36} & \multirow{2}{*}{1.000} \\
\hline & No & 24 & 96.0 & 23 & 92.0 & & \\
\hline
\end{tabular}


Also, 28-day mortality and 60-day mortality were similar in both groups with no significant differences (Table 8).

Table (8): Comparison of mortality in studied groups.

\begin{tabular}{|c|c|c|c|c|c|c|c|}
\hline \multirow{2}{*}{\multicolumn{2}{|c|}{ Variables }} & \multicolumn{2}{|c|}{$\begin{array}{c}\text { Group A (APRV) } \\
(n=25)\end{array}$} & \multicolumn{2}{|c|}{$\begin{array}{c}\text { Group B (SIMV) } \\
(\mathbf{n}=25)\end{array}$} & \multirow[t]{2}{*}{ FET } & \multirow[t]{2}{*}{ P-value } \\
\hline & & No & $\%$ & No & $\%$ & & \\
\hline \multirow{2}{*}{ 28-day mortality } & Yes & 9 & 36.0 & 11 & 44.0 & \multirow{2}{*}{0.33} & \multirow{2}{*}{0.773} \\
\hline & No & 16 & 64.0 & 14 & 56.0 & & \\
\hline \multirow{2}{*}{ 60-day mortality } & Yes & 11 & 44.0 & 13 & 52.0 & \multirow{2}{*}{0.32} & \multirow{2}{*}{0.778} \\
\hline & No & 14 & 56.0 & 12 & 48.0 & & \\
\hline
\end{tabular}

\section{DISCUSSION}

In the present study there were no differences between studied groups in demographic data and baseline clinical characteristics, gasometric variables, APACHE III score and LIS. After 24 hours LIS was significantly improved with APRV $(p=0.042)$. This could be explained by significant improvement in oxygenation and lung compliance in APRV treated patients, which are the main components of LIS. Follow up of LIS after 24 hours was done by Li et al. and showed significant improvement in APRV group $(p=$ $0.003)^{(5)}$.

Also, follow up 24 hours after ventilation revealed improvement of clinical variables $H R, R R$ and MAP with non-significant differences between groups. It was thought that increased mean airway pressure and intrathoracic pressure during APRV may decrease venous return and cardiac output. However, it is proved that APRV does not adversely affect the hemodynamics and may even improve them because of allowed spontaneous breathing. This is in agreement with findings of previous studies ${ }^{(5-13)}$. They found no existence of any serious adverse effects to the hemodynamics with APRV, and even APRV may improve them ${ }^{(14)}$. Role of spontaneous breathing in improving hemodynamics of mechanically ventilated ARDS patients was proved by various studies $(\mathbf{1 5}, \mathbf{1 6}$. Hering $\boldsymbol{e t} \boldsymbol{a l}$. in their crossover study reported better cardiac filling during APRV with spontaneous breaths than during APRV without spontaneous breaths and explained that by the effect negative inspiratory pressure generated by spontaneous breathing ${ }^{(\mathbf{1 7})}$.

Follow up of $\mathrm{pH}$ and $\mathrm{PaCO}_{2}$ was done after 24 hours of ventilation and no significant differences were noted between groups. Several trials that studied the impact of APRV on $\mathrm{pH}$ and $\mathrm{PaCO}_{2}$ had the same results like our study ${ }^{(10,14)}$. Other studies reported that APRV was associated with higher $\mathrm{pH}$ and lower $\mathrm{PaCO}_{2}$ than SIMV with low tidal volume ventilation ${ }^{(8)}$ or the reverse ${ }^{(\mathbf{1 8})}$ during the same period; however, the APRV methodology used in these studies was outdated.

In the present study no significant differences were reported between studied groups regarding the baseline $\mathrm{PaO}_{2} / \mathrm{FIO}_{2}$ ratio; however, $\mathrm{PaO}_{2} / \mathrm{FIO}_{2}$ ratio was improved significantly with APRV after 24 hours follow up ( $\mathrm{P}<0.001)$, which is in agreement with previously reported findings of various APRV studies $(5,9,10,14,19-21)$.

Myers and MacIntyre in their study, data from many clinical crossover studies showed that APRV produced better oxygenation than conventional ventilation modes probably due to mean pressure generated by the prolonged time of inflation and the improved distribution during spontaneous breathing ${ }^{(22)}$. Yoshida et al. in their study included 18 patients with ALI/ARDS, managed by APRV or PSV and had a computed tomography scan follow up. They illustrated that atelectasis were significantly decreased and aerated volume was increased with APRV ${ }^{(23)}$. Other results of two small randomized trials by Maxwell et $\boldsymbol{a l} .{ }^{(18)}$ and Song et al ${ }^{(\mathbf{1 3 )}}$ revealed that APRV had no significant advantages over low tidal volume ventilation (SIMV) regarding improvement of oxygenation. However, these studies were limited by small samples size and use of outdated APRV methodology.

In the present study there was no significant difference between groups regarding hospital length of stay. However, APRV in group (A) was significantly associated with a less ICU length of stay (days), more ICU-free days, less total ventilator days and more ventilator free days at day 28 in comparison to SIMV+PEEP in (B) group. Also, there was a significant increase in number of sedation free days with APRV in (A) group. These findings could be explained by ability of APRV to improve oxygenation and compliance of the respiratory system; also APRV allows spontaneous breathing and this reduces needs for both sedation and mechanical ventilation ${ }^{(9,12)}$.

No significant differences were identified between groups regarding the rate of successful extubation, rate of tracheostomy and incidence of pneumothorax. Also, 28-day mortality and 60-day mortality were similar in both groups with no significant differences.

Various studies are in agreement with these results ${ }^{(5,9,}$ 12, 14, 22); however, Zhou et al. ${ }^{(14)}$ showed that APRV had a higher rate of successful extubation and lower rate of tracheostomy than LTV $(\mathrm{P}=0.001)$. However, this was related to high rates of tracheostomy and failure of 
extubation in LTV group than that reported in the Lung Safe study ${ }^{(24)}$.

Unlike our results Liu et al. demonstrated that APRV and SIMV were associated with similar duration of ventilation $(\mathrm{P}=0.58)$ and ICU stay $(\mathrm{P}=0.75)$; however, ICU mortality was significantly lower in the APRV group than in the SIMV group $(\mathrm{p}=0.05)$. Differences in the results may be due to differences in the severity of ARDS in included patients ${ }^{(\mathbf{1 0})}$

Contrary to our results, González et al. in an observational study; they reported no differences between APRV and assist-control ventilation in the most of clinical outcomes like days of ventilation, length of stay in the ICU and incidence of ICU or hospital mortality. Also, period of hospital stay was increased in the APRV group by 1 day; however, patients in their study had a broad range of causes of respiratory failure. Also, the used methods of application, modification and weaning from APRV were different between ICUs and most of these methods are outdated. They also found a higher rate of tracheostomy in the APRV group ( $\mathrm{p}=0.007)$; however, the rate of tracheostomy is related to local practice rather than the used ventilation mode ${ }^{(20)}$.

In a retrospective review by Maung et al. they concluded that ventilator days were significantly greater with APRV when compared to assist control volume ventilation $(\mathrm{p}<0.001)$; however, patients included in the APRV were previously more diseased than those in the conventional ventilation group, also, weaning method in the APRV group was based only on physician experience without definitive protocol ${ }^{(11)}$.

Andrews et al. in their observational study, they concluded that the early use of APRV decreased mortality associated with ARDS when compared to conventional ventilation modes. However, this study has some limitations. Firstly, the study was conducted on trauma patients that had ARDS; however, ARDS has many different causes. Secondly, study compared a small sample size of 231 patients in the APRV group to a large sample size of $46,000+$ in the conventional ventilation group. Lastly, strategies were used in some patients before evident ARDS and conventional ventilation methods were not defined clearly ${ }^{(25)}$.

Also, unlike results of the present study, Varpula et al. demonstrated that no differences in clinical outcomes (ventilator-free days, use of sedatives and all physiological variables) were present when APRV was compared to SIMV in ALI/ARDS patients. Differences in the results of the present study and those of Varpula et al. may be due to differences in the severity of ARDS in included patients ${ }^{(26)}$.

Maxwell et al. studied the outcome of APRV and low tidal volume ventilation (SIMV with pressure support) in adult trauma patients with ARDS. APRV patients had more ventilator days and ICU LOS and the need for sedatives was similar in both groups. This may be explained by initial worse condition of APRV patients (higher APACHE II score), also the APRV methods used in that study were outdated ${ }^{(\mathbf{1 8})}$.

\section{CONCLUSION}

APRV can be used safely in ARDS without adverse effects on hemodynamics or arterial blood gases; moreover it can significantly improve oxygenation. Also, APRV use is associated with a less ICU length of stay, more ICU-free days, less time of ventilation, more ventilator-free days and more days without sedatives in comparison to conventional ventilation (SIMV+PEEP). However, APRV has no advantages over conventional ventilation regarding mortality outcome or hospital length of stay.

\section{REFERENCES}

1. Fan E, Needham DM, Stewart TE (2005): Ventilatory management of acute lung injury and acute respiratory distress syndrome. JAMA., 294:2889-2896.

2. The Acute Respiratory Distress Syndrome Network (2000): Ventilation with lower tidal volumes as compared with traditional tidal volumes for acute lung injury and the acute respiratory distress syndrome. $\mathrm{N}$ Engl J Med., 342:1301-1308.

3. Habashi NM (2005): Other approaches to open-lung ventilation: airway pressure release ventilation. Crit Care Med., 33(3):S228-S240.

4. Daoud E, Farag H, Chatburn R (2012): Airway Pressure release Ventilation: What Do We Know?.Respir Care, 57: 282-292.

5. Li JQ, Li N, Han GJ, Pan CG, Zhang YH, Shi XZ, Xu JY, Lu B, Li MQ (2016): Clinical research about airway pressure release ventilation for moderate to severe acute respiratory distress syndrome. European Review for Medical and Pharmacological Sciences, 20:2634-2641.

6. Kamath SS, Super DM, Mhanna MJ (2010): Effects of airway pressure release ventilation on blood pressure and urine output in children. Pediatr Pulmo., 45:48-54.

7. Calzia E, Pradermacher P (1997): Airway pressure release ventilation and biphasic positive airway pressure: a 10-year literature review. Clin Intensive Care, 8:296301 .

8. Hussein Kh, Mohamed Sh, Ahmed Y (2015): Airway pressure release ventilation in management of acute respiratory distress syndrome: a 2-Years Experience From Upper Egypt. International Journal of Scientific Research, 4(1):2277-8179.

9. Putensen C, Zech C, Wrigge H, Zinserling J, Stüber F, Von Spiegel T (2001): Long term effects of spontaneous breathing during ventilatory support in patients with acute lung injury. Am J Respir Crit Care Med., 164:43-9.

10. Liu L, Tanigawa $K$, Ota $K$, Tamura T, Yamaga $S$, Kida Y, Kondo T, Ishida M et al. (2009): Practical use of airway pressure release ventilation for severe ARDS: a preliminary report in comparison with a conventional ventilatory support. Hiroshima J Med Sci., 58(4)83-88.

11. Maung AA, Schuster KM, Kaplan LJ, Ditillo MF, Piper GL, Maerz LL, Lui FY, Johnson DC, Davis KA (2012): Compared to conventional ventilation airway 
pressure release ventilation may increase ventilator days in trauma patients. J Trauma Acute Care Surg., 73(2):507-510.

12. Kaplan LJ, Bailey H, Formosa V (2001): Airway pressure release ventilation increases cardiac performance in patients with acute lung injury/adult respiratory distress syndrome. Critical Care, 5:221-226.

13. Song S, Tian H, Yang $X$, Hu Z (2016): The clinical effect of airway pressure release ventilation for acute lung injury/acute respiratory distress syndrome. Chin Crit Care Med., 28(1):15-21.

14. Zhou Y, Jin X, Lv Y, Wang P, Yang Y, Liang G, Wang B, Kang Y (2017): Early application of airway pressure release ventilation may reduce the duration of mechanical ventilation in acute respiratory distress syndrome. Intensive Care Med., 43:1648-59.

15. Kallet RH (2011): Patient-ventilator interaction during acute lung injury and the role of spontaneous breathing, part 1: respiratory muscle functions during critical illness. Respir Care, 56:181-189.

16. Putensen $\mathrm{C}$, Mutz N, Putensen-Himmer G, Zinserling J (1999): Spontaneous breathing during ventilatory support improves ventilation/perfusion distribution in patients with ARDS. Am J Respir Crit Care Med., 159:1241-1248.

17. Hering $\mathbf{R}$, Peters $\mathrm{D}$, Zinserling $\mathrm{J}$, Wrigge $\mathbf{H}$, von Spiegel T, Putensen C (2002): Effects of spontaneous breathing during airway pressure release ventilation on renal perfusion and function in patients with acute lung injury. Intensive Care Med., 28(10):1426-1433.

18. Maxwell RA, Green JM, Waldrop J, Dart BW, Smith PW, Brooks D, Lewis PL, Barker DE (2010): A randomized prospective trial of airway pressure release ventilation and low tidal volume ventilation in adult trauma patients with acute respiratory failure. J Trauma, 69:501-11.

19. Varpula T, Jousela I, Niemi R, Takkunen O, Pettil V (2003): Combined effects of prone positioning and airway pressure release ventilation on gas exchange in patients with acute lung injury. Acta Anaesthesiol Scand., 47:516-524.

20. González M, Arroliga AC, Frutos-Vivar $\mathrm{F}$ et al. (2010): Airway pressure release ventilation versus assist-control ventilation: a comparative propensity score and international cohort study. Intensive Care Med., 36:817-827.

21. Dart BW, Maxwell RA, Richart CM, Brooks DK, Ciraulo DL, Barker DE, Burns RP (2005): Preliminary experience with airway pressure release ventilation in a trauma/surgical intensive care unit. J Trauma, 59(1):71-76.

22. Myers TR and MacIntyre NR (2007): Does airway pressure release ventilation offer important new advantages in mechanical ventilator Support?. Respir Care, 52(4):452-458.

23. Yoshida T, Rinka H, Kaji A, Yoshimoto A, Arimoto H, Miyaichi T, Kan M (2009): The impact of spontaneous ventilation on distribution of lung aeration in patients with acute respiratory distress syndrome: airway pressure release ventilation versus pressure support ventilation. Anesth Analg., 109(6):1892-900.

24. Bellani G, Laffey JG, Pham T et al. (2016): Epidemiology, patterns of care and mortality for patients with acute respiratory distress syndrome in intensive care units in 50 countries. JAMA., 315:788-800.

25. Andrews PL, Shiber JR, Jaruga-Killeen E, Roy S, Sadowitz B, O'Toole RV, Gatto LA, Nieman GF, Scalea T , Habashi NM (2013): Early application of airway pressure release ventilation may reduce mortality in high-risk trauma patients. J Trauma Acute Care Surg., 75:635-641.

26. Varpula $T$, Valta $P$, Niemi $R$, Takkunen $O$, Hynynen $M$ and Pettila VV (2004): Airway pressure release ventilation as a primary ventilator mode in acute respiratory distress syndrome. Acta Anaesthesiol Scand., 48:722-731. 